\title{
Zum 3. Mal - das Greifswalder Ryck- Symposium am 2. und 3. September 2016
}

\section{Und diesmal neu mit 3 Hands-On-Workshops}

Am Freitag beginnt ein breit gefächertes 2-tägiges Vortragsprogramm für MTRA, welches in diesem Jahr erstmalig durch 3 Hands-on Workshops ergänzt wird. Somit kann sicherlich jeder etwas Neues, Nützliches oder Interessantes für seine tägliche Arbeit mit nach Hause nehmen.

In den Pausen präsentieren an beiden Tagen die Vertreter der Industrie ihre Pro-

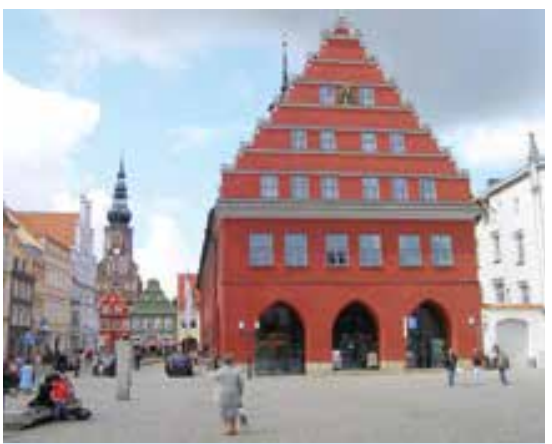

Greifswald - immer eine Reise wert dukte und stehen für Ihre Fragen zur Verfügung. Zum Abschluss wird der Tag dann durch einen Segeltörn mit dem schönen Segelschiff „Weiße Düne“ auf dem Greifswalder Bodden, dem Tor zur Ostsee, abgerundet.

Am Samstagmorgen beginnt der Tag mit der Praxis. So wird in kleinen Gruppen z.B. am Gefäßmodell praktische Materialkunde in der Angiografie vermittelt. Oder man kann sich praktische Tipps für die Patientenumlagerung mit Hilfsmitteln und Kinästhetik holen. Eine weitere Kleingruppe kann erste eigene Erfahrungen mit dem Ultraschallkopf machen, bevor es dann wieder mit den theoretischen Vorträgen zu aktuellen Themen weitergeht.

Allen, die eine etwas längere Anreise nach Greifswald haben, sei eine kleine Aufenthaltsverlängerung empfohlen, denn die reizvolle Umgebung hält viele Überraschungen bereit.

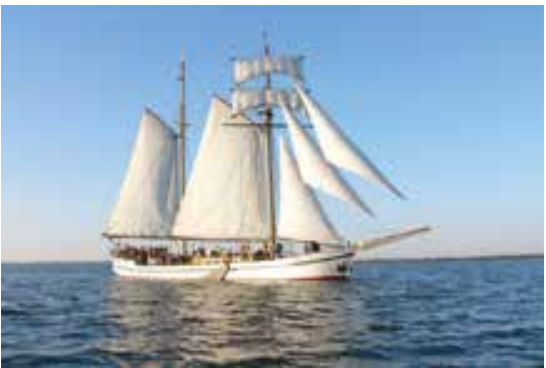

Auf dem Segelschiff „Weiße Düne“ heißt es auch in diesem Jahr wieder „Leinen los!“

Also, melden Sie sich bald an, da die Teilnehmerzahlen begrenzt sind.

Wir freuen uns auf Sie!

Herzlichst

Prof. Dr. Norbert Hosten

Brigitte Olbrich

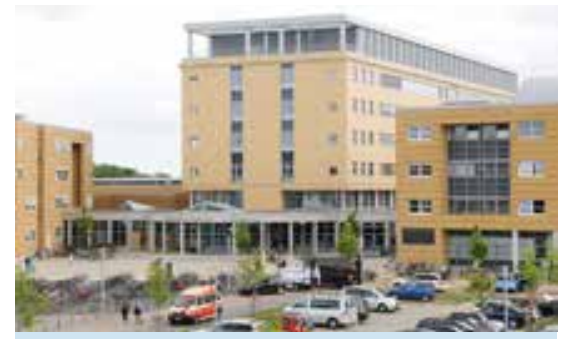

Die Heimat des Ryck-Symposiums: Das Klinikum der Ernst-Moritz-Arndt-Universität Greifswald 